\title{
Genetics, diagnosis and treatment of Lynch syndrome: Old lessons and current challenges (Review)
}

\author{
FRANCESCA DURATURO $^{1}$, RAFFAELLA LICCARDO ${ }^{1}$, MARINA DE ROSA $^{1}$ and PAOLA IZZO ${ }^{1,2}$ \\ ${ }^{1}$ Department of Molecular Medicine and Medical Biotechnology; \\ ${ }^{2}$ CEINGE Biotecnologie Avanzate, University of Naples 'Federico II', Naples I-80131, Italy
}

Received June 21, 2018; Accepted December 20, 2018

DOI: $10.3892 / 01.2019 .9945$

\begin{abstract}
Lynch syndrome (LS) is an autosomal dominant genetic disorder associated with germline mutations in DNA mismatch repair (MMR) genes. The carriers of pathogenic mutations in these genes have an increased risk of developing a colorectal cancer and/or LS-associated cancer. The LS-associated cancer types include carcinomas of the endometrium, small intestine, stomach, pancreas and biliary tract, ovary, brain, upper urinary tract and skin. The criteria for the clinical diagnosis of LS and the procedures of the genetic testing for identification of pathogenetic mutations carriers in MMR genes have long been known. A crucial point in the mutation detection analysis is the correct definition of the pathogenecity associated with MMR genetic variants, especially in order to include the mutation carriers in the endoscopy surveillance programs more suited to them. Therefore, this may help to improve the LS-associated cancer prevention programs. In the present review, we also report the recent discoveries in molecular genetics of LS, such as the new roles of MMR protein and immune response of MMR repair deficiency in colorectal cancer. Finally, we discuss the main therapeutic approaches, including immunotherapy, which represent a valid alternative to traditional therapeutic methods and extend the life expectancy of patients that have already developed LS-associated colorectal cancer.
\end{abstract}

\section{Contents}

1. Lynch syndrome: An overview

2. Clinical diagnosis and molecular analysis of Lynch syndrome

Correspondence to: Dr Francesca Duraturo, Department of Molecular Medicine and Medical Biotechnology, University of Naples 'Federico II', 5 Via Pansini, Naples I-80131, Italy

E-mail: francesca.duraturo@unina.it

Key words: Lynch syndrome, mismatch repair genes, correlation genotype-phenotype, unclassified genetic variants, immunotherapy, highly immunogenic frame-shift neo-peptides
3. Recent discoveries in molecular genetics of Lynch syndrome

4. Management of Lynch syndrome patient with CRC

5. Conclusions

\section{Lynch syndrome: An overview}

Clinical features. Lynch syndrome (LS) is the most common hereditary form of colorectal cancer (CRC) with an incidence of 3-5\% of all CRC, followed by Familial Adenomatous Polyposis (FAP), which accounts for less than $1 \%$ of the total CRC. LS and FAP are autosomal dominant inheritance diseases, caused by germline mutations in the DNA mismatch repair (MMR) genes and the tumor suppressor gene Adenomatous Polyposis Coli (APC), respectively (1-2). LS is also known as hereditary non-polyposis colorectal cancer (HNPCC) to highlight the absence of colon polyps and to distinguish this syndrome from FAP characterized by 100-1,000 polyps (1-4) and other hereditary syndrome of colorectal cancer, such as hamartomatous polyposis syndrome (5-7). LS patients born with a germline mutation in one of these MMR genes, and acquire inactivation of the second wild-type allele in their tumoral DNA, fulfilling Knudson's two hit hypothesis for inactivation of tumor suppressor genes. The somatic inactivation of the corresponding wild-type allele occurs almost exclusively by small mutations or (partial) gene loss, and bi-allelic inactivation then leads to complete abolition of the protein function of MMR system (3). This results in a defective DNA MMR system. LS is characterized by a high lifetime risk for tumor development, especially in the case of CRC (20-70\% with average age at diagnosis 44-61), endometrial cancer (15-70\% with average age at diagnosis 48-62), gastric cancer (6-13\% with average age at diagnosis 56), ovarian cancer (4-12\% with average age at diagnosis 42,5) and other extracolonic tumors (total risk $15 \%$ ) as small intestine, brain, skin hepatobiliary and urinary tract (1). Other phenotypic features of LS subjects are preferential tumor localization in the right-sided colon, presence of multiple synchronous and metachronous colorectal cancers, poorly differentiated tumors, with a marked lymphocytic peritumoral inflammation recalling features of so-called 'Crohn's reaction' and Microsatellite instability at somatic level $(8,9)$.

Genetic bases. LS patients present with a germline mutation in one of the MMR genes, MLH1 on chromosome $3 p 21$, 
MSH2 on chromosome $2 p 16$, MSH6 on chromosome $2 p 16$, $P M S 2$ on chromosome $7 p 22, M L H 3$ on chromosome $2 p 16$ and $\mathrm{MSH} 3$ on chromosome 5q11. The heteroduplex MutSa that predominantly identifies single base mispairings is formed by $M S H 2$ and $M S H 6$ proteins, while $M S H 2$ with $\mathrm{MSH} 3$ form the MutS $\beta$ identifying short insertions or deletions. imilar, the MutL $\alpha$ and MutL $\gamma$ subunits are formed by MLH1-PMS2 and MLH1-MLH3, respectively, they interacts with the MutS $\alpha$ or MutS $\beta$ complex, stimulating excision and resynthesis of abnormal DNA (10). MSH2 and $M L H 1$ are, thus essential for both complexes to function. Therefore, the $M M R$ genes, $M L H 1$ and $M S H 2$ are defined as 'major' $M M R$ genes, while the MSH6, PMS2, MLH3 and MSH3 are known as 'minor' $M M R$ genes (9). Somatic inactivation of the corresponding wild-type allele occurs almost exclusively through point mutations or (partial) gene loss; bi-allelic inactivation then leads to complete abolition of the protein function. This results in a defective DNA MMR system, since MMR proteins are involved in the correction of single nucleotide mismatches and small insertions or deletions that may arise during DNA replication (11). The absence of redundant functions for MSH2 and MLH1 proteins underlies the importance of these two genes in MMR complex. Majority of mutations was found in these genes ( 84 and $71 \%$ respectively). Carriers of MSH2 variants show a higher incidence of extracolonic malignancy (48-61\%; endometrial, gastric, ovarian and kidney cancer) than the carrier of MLH1 variants (11-42\%) (12). Regard to minor genes, the MSH6 variants, until a few years ago, seemed to cause a form of 'attenuated' LS (13), PMS2 variants were associated with combined presence of multiple colorectal adenomas and glioblastomas (14). Recently, also mutations in MLH3 gene have been associated with brain tumors (15). MSH3 variants were associated with a classic phenotype only if they were inherited in combination with MSH2 variants (16). Recently, it was showed that biallelic mutations in MSH3 gene are causing polyposis forms similar to FAP phenotype (17). Sometimes costitutional MLH1 methylation in the LS adenomas could represent the initiation of these neoplasms and it may present as a defect that was inherited (18).

Microsatellite instability of related-LS tumors. The deficiency of MMR complex determines high rate of mutations in repetitive DNA sequences known as microsatellites. This condition is known as microsatellite instability (MSI) and is present in approximately $95 \%$ of all LS-associated cancers (18). Many genes contain repetitive sequences in their coding regions and some of these have an important role in the regulation of cell growth (19). In fact, mutations in the TGF $\beta R I I$ and $T C F-4$ genes, that normally inhibit cell growth, and in the IGF-RII and $B A X$ genes involved in the apoptotic process (20) particularly predispose to colon cancer. Moreover, the presence of polyadenine traits in the coding sequences of the minor MMR genes, MSH6, MLH3 and MSH3, makes the same MMR genes targets of the MSI phenotype $(21,22)$.

The sporadic CRC also display an MSI phenotype in about $15 \%$. In this case, the MSI may be result of somatic hypermethylation of the $M L H 1$ gene promoter. The hypermethylation at the promoter of MLH1 allele lead to silencing expression from that allele in all main somatic tissues. In
$40-87 \%$ of all sporadic microsatellite unstable tumors (23) with hypermethylation of the $M L H$ lgene is present a specific mutation in the BRAF oncogene, usually the V600E missense mutation. This mutation is not present in LS MSI tumors in which the MSI phenotype is due to genetic alteration of MMR genes and it is not depend by epimutation (24).

Finally, another type of instability, 'elevated microsatellite alterations at selected tetranucleotide repeats' (EMAST), has also been identified in colon cancers. EMAST has been associated with both MSI. One known cause of EMAST is a deficiency or dysfunction of $M S H 3$, which is required in the repair of tetranucleotide repeat mismatches in complex with $M S H 2$. The MSH3 defect may also cause an impairment of homologous repair and increase sensitivity to some targeted therapies, such as poly (ADP-ribose) polymerase 1 (PARP1) inhibitors (25).

\section{Clinical diagnosis and molecular analysis of Lynch syndrome}

Clinical criteria. Identification of families affected by LS occurs by the Amsterdam Criteria (AC) and Bethesda guidelines. The clinical criteria of Amsterdam were used to identify families eligible for molecular analysis since 1990 (26). Subsequently, these criteria were modified, the AC II in order to include the other LS-related cancers (27). The Bethesda guidelines, which were less restrictive than $\mathrm{AC}$, were later defined (28) and take into account the MSI-status detected at tumoral tissue. The 'Panel of Bethesda' recommended by the National Cancer Institute include five microsatellites: two mononucleotide repeats (BAT25, BAT26) and three dinucleotide repeats (D2S123, D17S250, D5S346) (29) that are analyzed on tumoral DNA of patients with likely LS. If at least two of these repeats (40\% of markers) are instability, tumoral DNA shows high instability (MSI-H), while if at least $10-30 \%$ of markers are instability, tumoral DNA shows low instability (MSI-L); when no microsatellite is instable, tumoral DNA shows stability of microsatellite sequences (MSS) (30). Subsequently, other microsatellite sequences were included in the panel test: NR21, NR22 and NR24, quasimonomorphic mononuceotide repeats in order to improve the sensitivity rate and predictive specificity of Bethesda guidelines $(31,32)$; these three repeats (NR21, NR22 and NR24) with BAT25 and BAT26 constitute the Pentaplex Panel (31).

Molecular analysis. LS is associated with mutations in MMR genes. Most of mutations were found in the $\mathrm{MLH1}$ and $\mathrm{MSH} 2$ genes that account for about 50 and $40 \%$ respectively of all mutations reported; about $15-20 \%$ of mutations were identified in the MSH6 and in PMS2 $(33,34)$; few pathogenetic mutations were identified in $M L H 3$ (15) gene and so far, only one heterozygous variant in $M S H 3$ gene was associated with LS phenotype (16). The most pathogenetic variants in $M M R$ genes are small insertions/deletions or large genetic rearrangements (large deletions/insertions) that, at protein level, result in premature stop codon formation $(35,36)$. Moreover, several mutations identified in MMR genes are missense, silent or intronic variants. The influence of these variants on the development of cancer is often a controversial topic; therefore, they are each classified as a variant of uncertain 
significance (VUS) (37). According to international recommandetions (Colon cancer Family Registry 2009, InSiGHT Variant Interpretation Committee 2011) it is possible to use a multifactorial likelihood model in an attempt to define a pathogenetic role of VUS (38). This approach is based on the evaluation of both phenotipic and functional features $(9,39)$. In particular, the segregation analysis should be considered the 'gold standard' for the validation of VUS pathogenecity $(34,39)$.

The loss of function of one MMR protein prevents to repair's complex to work properly and this determines a genetic instability known as MSI at somatic level (27).

The molecular analysis to make diagnosis of LS begins with the evaluation of the MSI status on tumoral DNA (see above) by DNA fragment analysis using capillary electrophoresis (38). At somatic level the MSI is detectable by immunohistochemistry (IHC) analysis (40). Instead, the common methods for the mutation detection analysis of MMR genes include the use of denaturing high-performance liquid chromatography (DHPLC) and direct sequencing for point mutations, and multiplex ligation-dependent probe amplification (MLPA) for large rearrangements $(16,35,36)$. So far, a large number of variants in Insight-group Database (www.insightgroup.org) have been reported in $M M R$ genes, in particular $M L H 1, M S H 2, M S H 6$ and PMS2, Table I, while no variants in the $M L H 3$ and $M S H 3$ genes have been reported. However, literature data show cases of patients with hereditary colorectal cancer and with mutations in these two genes $(15,16)$.

Today, high-throughput techniques, such as next generation sequencing, have been substituted for these methods to allow the identification of a major number of genes involved in such hereditary cancer forms. For example, recent findings suggested POLE and POLD1 mutations are associated with gastrointestinal malignancies, with mutations in these genes having been identified in subjects with a Lynch-like phenotype (41).

\section{Recent discoveries in molecular genetics of Lynch syndrome}

New roles for MMR proteins. It is known a long time that MMR proteins have developed various other functions in addition to the postreplicative repair. Among these new roles (such as prevention of reparative recombination, promotion of meiotic crossover, expansion of repeated triplets, modulation of microRNA biogenesis) is included the immunoglobulin (Ig) diversification based on the 'somatic hypermutation' (SHM) process. This process is regulated by the MutSa -MutL $\alpha$ complex, in combination with two other proteins, AID (activation-induced cytidine deaminase) and Pol $\mu$ (DNA Polymerase 'error-prone') (42); in particular, MutS $\alpha$ deficiency is associated with neoplastic transformation of $\mathrm{T}$ lymphocytes (43). Paradoxically, MMR maintains stability throughout the genome but is responsible for up to $60 \%$ of the mutations in $\mathrm{V}$ and $\mathrm{S}$ regions of the Ig locus that are important for diversification antibodies (44). Therefore, a better understanding of the intricate signaling cascades that govern antibody diversification could help uncover the associations between the maintenance of genomic integrity and tumorigenesis in the adaptive immune response.
Table I. Numbers of genetic variants identified in MMR genes.

Total no. of

\begin{tabular}{lcc} 
Gene & Accession number & genetic variants \\
\hline MLH1 & NM_000249.3 & 8,023 \\
MSH2 & NM_000251.2 & 6,346 \\
MSH6 & NM_000179.2 & 2,297 \\
PMS2 & NM_000535.5 & 1,264 \\
\hline
\end{tabular}

All data were retrived from the Insight Database.

Immune-response in LS colorectal cancer. LS cancers are usually referred to as MSI-H or MSI and conceptually display a very interesting biology and clinical behavior that is governed by the underlying mutational mechanism of these tumors. MMR-deficient cells accumulate an abundance of mutations at coding microsatellites, also found in tumor-relevant genes. These mutations may give rise to a loss of function of the respective proteins but may also trigger the translation of highly immunogenic frameshift neo-peptides or -antigens (FSPs) (45). Such FSP antigens may be shared if they occur in genes for which the mutational inactivation has a growth-promoting impact that is supportive for the development of a neoplasm. Such shared antigens may thus occur in multiple and independently arising MMR-deficient tumors. FSP neo-antigens are highly immunogenic due to long mutational antigens that encompass multiple potential epitopes (46). As these FSPs are derived from real shifts of the reading frame of the respective gene, they usually have a completely novel, and for the affected organism, foreign amino acid sequence, that results from insertions or deletions of single, individual nucleotides that alter the reading frame of the affected genes (Fig. 1). Such frame-shift mutations therefore generated substantially more immunogenic antigens in comparison, for example, to single missense mutations as they, for example, frequently occur in mutant P53 or KRAS genes. If one considers MMR deficiency as a unique mechanism of carcinogenesis, one can imagine that at the beginning of the carcinogenic process cell clones are generated that acquire mutations in coding microsatellites on a more random basis. Only cells in which the mutational spectrum favours neoplastic growth features will survive and further expand, whereas other cells with less favourable mutational spectra will be lost. Over time, this mechanism drives and shapes the mutational spectrum of the surviving cell clones into a better and better adapted status for local growth requirements. Thus, loss of the MMR system could represent an efficient mutational mechanism allows for a Darwinian selection process of carcinogenesis. The extensive generation of these neo-antigens in MSI cancers explains the pathological finding that MSI cancers are characterized by massive infiltration of lymphocytes and other immune-related cells that point to the strong immunogenicity of such cancers. MSI cancer cells can grow out to clinically manifest cancers if local $\mathrm{T}$ cells in their environment become exhausted. Alternatively, MSI cancer cells that have undergone immune evasion due to a loss of HLA-mediated antigen presentation may grow out irrespective 

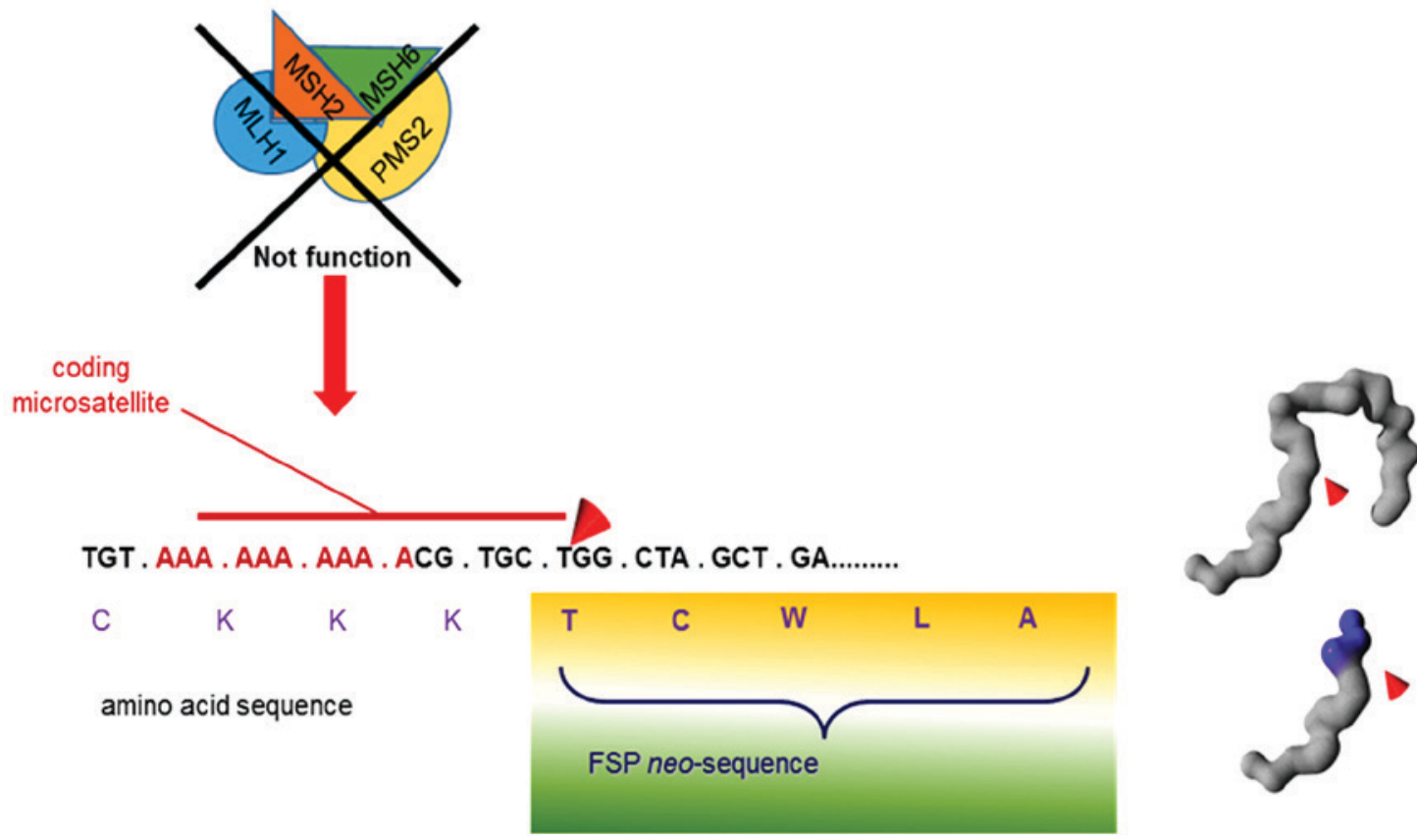

Figure 1. Mismatch repair-deficient cells accumulate an abundance of mutations at coding microsatellites that may give rise to a loss of function of the respective proteins; however, may additionally trigger the translation of highly immunogenic FSPs or -antigens. FSP, frameshift neo-peptide.

of local $\mathrm{T}$ cell surveillance (47). Indeed, direct and indirect molecular mechanisms do not structurally interfere with the tumor cells' capacity to present FSP neoantigens, but influence the $\mathrm{T}$ cell activation status. In approximately $30 \% \mathrm{LS}$ tumoral tissue mutation-induced loss of Beta 2 Microglobulin (B2M), the essential light chain of HLA class I antigens, induces a complete lack of assembled HLA class I antigens on the tumor cell surface. As a consequence, CD8-positive T cells cannot attack B2M-mutant LS cancer cells. Even mutations of the genes CIITA and RFX5, which are required for functional HLA class II antigen expression on the tumor cell surface, are found in up to $20 \%$ of MSI colorectal cancers and associated with a complete loss of HLA class II antigens on the tumor cell surface, consequently the inactivation of CD4-positive $\mathrm{T}$ cell (48). This may justify an endogenous immune antitumor response, counterbalanced by the expression of inhibitory immune signals, such as PD-1 binding to the PD-L1 receptor present on the lymphocyte membrane, inhibiting its production (Fig. 2). Immune checkpoints play a key role in limiting antitumor immunologic responses, such as those directed against cytotoxic T-lymphocyte antigen 4 (CTLA-4) and programmed cell death-1 (PD-1) receptor and its ligand, PD-L . The ligation of T-cell PD-1 by the tumor results in the downregulation of T-cell effector functions that can destroy tumor tissue. Therefore, the blockade of this pathway by anti-PD-1 antibodies prevents this downregulation, and allows $\mathrm{T}$ cells to maintain their antitumor functionality and ability to mediate tumor cell death $(48,49)$.

\section{Management of Lynch syndrome patient with CRC}

The early detection of $L S$-mediated CRC progression. To improve the quality of care of patients and families with any hereditary condition resulting in gastrointestinal tumours as Lynch syndrome is the identification of carriers of relevant

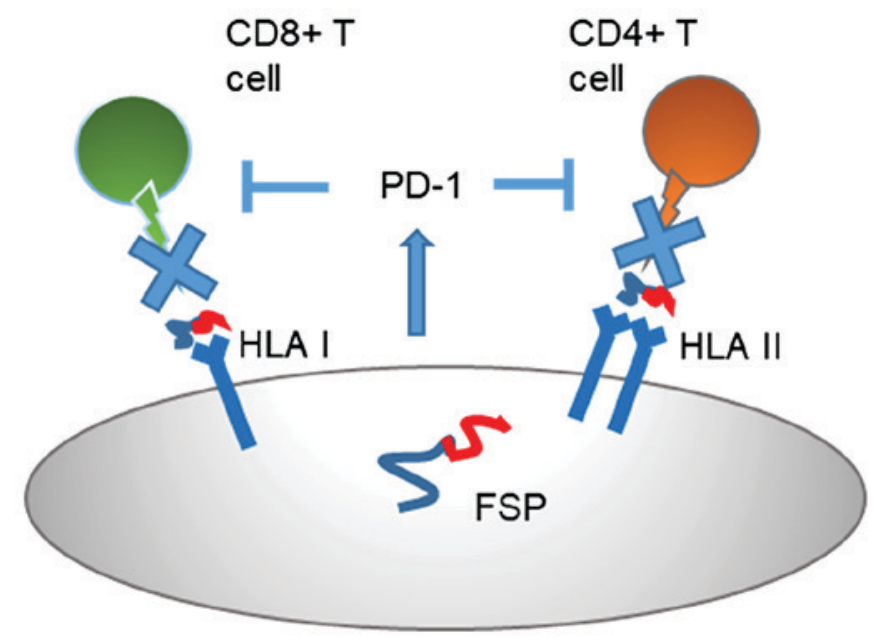

Figure 2. In tumoral cells, the ligation of T-cell PD-1 results in the downregulation of T-cell (CD8+ and CD4+) effector functions that may destroy tumor tissue; this downregulation of T-cell may favor the neoplastic expansion. PD-1, programmed cell death-1; FSP, frameshift neo-peptide.

predisposition alleles (50). The purpose of this is reducing MMR associated hereditary colorectal cancer mortality. It is known a long time that carrier subjects of pathogenetic mutation in a MMR gene undergone to recommends annual surveillance colonoscopy from age 25 years (51). In order to include the mutation carriers in the endoscopy surveillance programs more suited to them, a crucial point is represented by correct definition of the pathogenecity of MMR genetic variants identified in the mutation detection analysis $(52,53)$. Thus, this knowledge may helpful to improve the related-LS cancer prevention programs. Recently, MSH6 and PMS2 mutation carriers have been reported to have a lower risk of CRC with a later age of presentation (54). Indeed, literature data support 


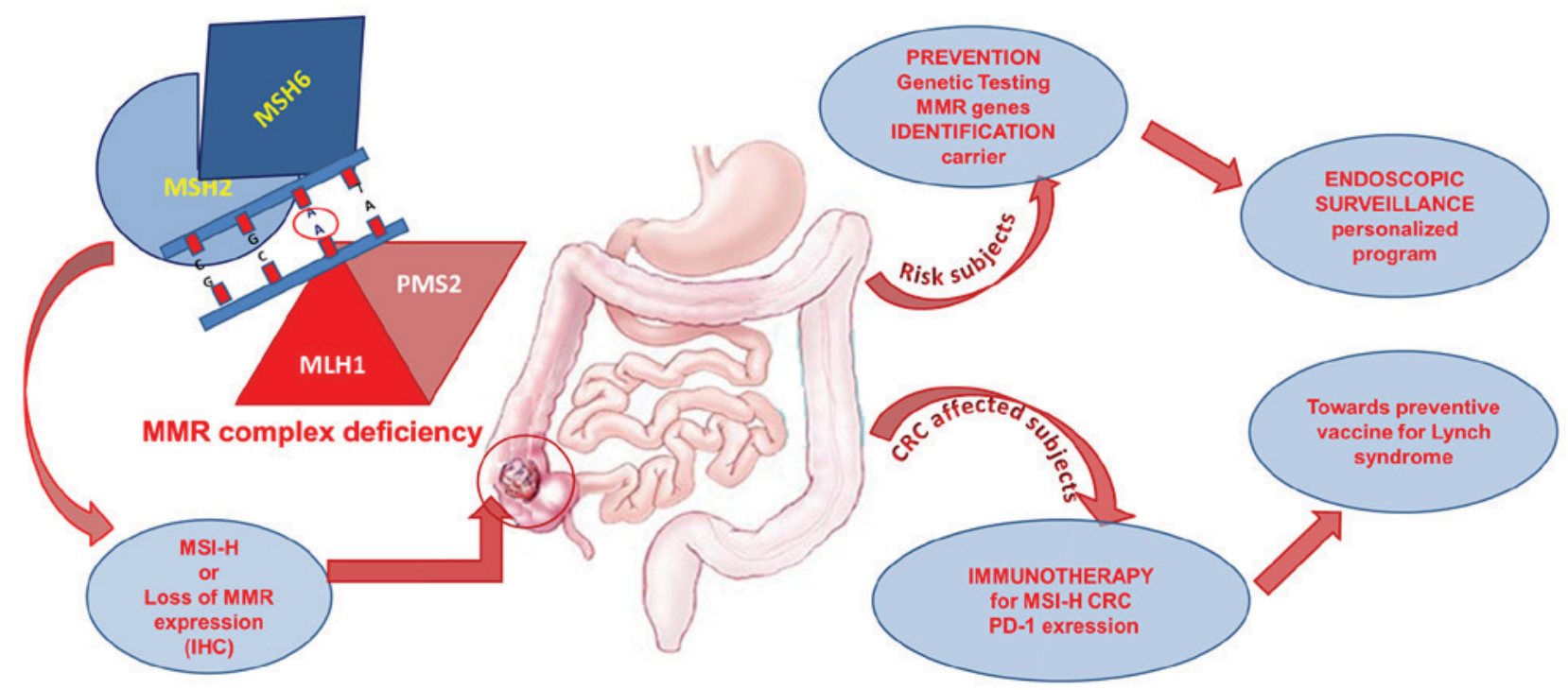

Figure 3. Management of patients with Lynch syndrome.

a move to commence colonoscopy surveillance in MSH6 and PMS2 mutation carriers at the older age of 30 years, providing no young index $\mathrm{CRC}$, and extend the interval to 2 years (55). Therefore, the classification of MMR genetic variants is many important to choose the most appropriate endoscopic surveillance program and to precede towards a personalized medicine (56) (Fig. 3).

Therapeutic approaches of $L S$-related colon cancer. The choose of the optimal treatment approach for patients with metastatic colorectal cancer is based on evaluation of clinical and genomic features of tumors. It is important to take into account of the side of the colon in which the primary tumor originates, the sites and burden of metastatic disease, by mutational status of some genes, as KRAS, BRAF (57) and the MSI status on tumoral DNA (58). The most applied protocol of adjuvant chemotherapy for colorectal cancer not metastatic (stage II) involves the administration of 5-fluorouracil (5FU). Instead in some metastatic CRC cases (stage III), systemic therapy with a FOLFOX- or CAPOX (capecitabine and oxaliplatin) regimen is the standard of care in these patients. Patients with left-sided and RAS wild-type tumors receive anti-epidermal growth factor receptor (EGFR)-directed therapy, while patients with right-sided tumors or those with RAS mutations receiving bevacizumab (59). In patients with tumors that manifest microsatellite instability or deficient mismatch repair, adjuvant chemotherapy with 5-fluorouracil did not result in a survival benefit in subgroup analyses of patients with colon cancer without metastasis. While, among patients with metastatic colon cancer who received the treatment with capecitabine and oxaliplatin, survival was significantly longer among those who had deficient mismatch repair than among those who had proficient mismatch repair.

These different features are probably related to the lymphocytic infiltrate characteristic of MMR-deficient tumors that determines an antitumor immune response that may be abrogated by the immunosuppressive effects of chemotherapy (60). Despite this enhanced immunogenicity, $\mathrm{T}$ cells are unable to eradicate these tumors, likely due to overexpression of immune checkpoint proteins that can be antagonized by checkpoint inhibitors (Fig. 2). Recently, immune checkpoint-inhibiting agents have been developed as antitumor drugs and appear promising, especially in sporadic CRC patients with MSI. Pembrolizumab (P) is an anti-PD-1 antibody that blocks the interaction between PD-1 on T-cells, and PD-L1 and PD-L2 on tumor cells. The antibody pembrolizumab has been evaluated in patients with metastatic colorectal cancer and MSI in whom previous treatment with cytotoxic agents had failed. The response to treatment was similar in patients with LS-related $\mathrm{CRC}$ and those sporadic CRC. Moreover, the combination of nivolumab, another anti-PD-1 antibody, plus ipilimumab, an anti-cytotoxic T-lymphocyte antigen 4 (CTLA-4) antibody, resulted in response rates and disease-control rates that were higher than those previously reported with nivolumab alone (61). In this context, it is interesting to note that this drugs show good results in the treatment of tumors with MSI (Fig. 3).

\section{Conclusions}

Identifying the mutation that causes clinical manifestations of Lynch syndrome is crucial given the relatively early onset of the disease, the high penetrance of mutations, as well as the proven efficiency of surveillance strategies. Furthermore, the studies carried out over the years on the molecular mechanisms underlying the onset of LS-related colorectal cancer have allowed us to make significant advances also in the therapeutic treatments of these tumors. Recently, immune checkpoint-inhibiting agents have been developed as antitumor drugs and appear promising, especially in sporadic CRC patients with MSI. Precisely because the subjects with Lynch syndrome show in $95 \%$ of cases MSI-H on the tumor tissue, we could say that they are ideal candidates for immunotherapeutic treatment. Finally, we hope in the near future in the context of this research will be possible to establish a preventive cancer vaccine for Lynch syndrome as recently reported by studies on the preclinical mouse model (62) (Fig. 3). 


\section{Acknowledgements}

Not applicable.

\section{Funding}

No funding was received.

\section{Availability of data and materials}

Not applicable.

\section{Authors' contributions}

FD and PI designed the review. RL and MDR preformed the literature search. FD and PI interpreted the scientific articles, and FD wrote the first draft of the manuscript. FD developed the structure of the paper and the discussion. RL, MDR and PI critically revised the manuscript. All authors read and approved the final manuscript.

\section{Ethics approval and consent to participate}

Not applicable.

\section{Patient consent for publication}

Not applicable.

\section{Competing interests}

The authors declare that they have no competing interests.

\section{References}

1. Kohlmann W and Gruber SB: Lynch Syndrome. In: Adam MP, Ardinger HH, Pagon RA, Wallace SE, Bean LJH, Stephens K, Amemiya A, editors. GeneReviews ${ }^{\circledR}$ [Internet]. Seattle (WA): University of Washington, Seattle; 1993-2018.

2. Dodaro C, Grifasi C, Florio J, Santangelo ML, Duraturo F, De Rosa M, Izzo P and Renda A: The role of mutation analysis of the APC gene in the management of FAP patients. A controversial issue. Ann Ital Chir 87: 321-325, 2016.

3. Lynch HT, Snyder CL, Shaw TG, Heinen CD and Hitchins MP: Milestones of Lynch syndrome: 1895-2015. Nat Rev Cancer 15: 181-194, 2015.

4. De Rosa M, Galatola M, Borriello S, Duraturo F, Masone S and Izzo P: Implication of adenomatous polyposis coli and MUTYH mutations in familial colorectal polyposis. Dis Colon Rectum 52: 268-274, 2009

5. Galatola M, Paparo L, Duraturo F, Turano M, Rossi GB, Izzo P and De Rosa M: Beta catenin and cytokine pathway dysregulation in patients with manifestations of the 'PTEN hamartoma tumor syndrome'. BMC Med Genet 13: 28, 2012.

6. Paparo L, Rossi GB, Delrio P, Rega D, Duraturo F, Liccardo R, Debellis M, Izzo P and De Rosa M: Differential expression of PTEN gene correlates with phenotypic heterogeneity in three cases of patients showing clinical manifestations of PTEN hamartoma tumour syndrome. Hered Cancer Clin Pract 11: 8, 2013.

7. Carlomagno N, Duraturo F, Candida M, De Rosa M, Varone V, Ciancia G, Calogero A and Santangelo ML: Multiple splenic hamartomas and familial adenomatous polyposis: A case report and review of the literature. J Med Case Rep 9: 154, 2015.

8. Cudia B, Liccardo R, Di Carlo G, Damiano G, Lo Monte AI, Izzo P and Duraturo F: Clinical and anamnestic evaluation rôle for the diagnosis and treatment of families affected by Lynch syndrome. Case report and review of the literature. Eur J Oncol 19: 265-271, 2014.
9. Liccardo R, De Rosa M, Izzo P and Duraturo F: Novel implications in molecular diagnosis of Lynch syndrome. Gastroenterol Res Pract 2017: 2595098, 2017.

10. Peltomäki P: Deficient DNA mismatch repair: A common etiologic factor for colon cancer. Hum Mol Genet 10: 735-740, 2001

11. Gupta R, Sinha S and Paul RN: The impact of microsatellite stability status in colorectal cancer. Curr Probl Cancer 42: 548-559, 2018.

12. Yurgelun MB, Kulke MH, Fuchs CS, Allen BA, Uno H, Hornick JL, Ukaegbu CI, Brais LK, McNamara PG, Mayer RJ, et al: Cancer susceptibility gene mutations in individuals with colorectal cancer. J Clin Oncol 35: 1086-1095, 2017.

13. Lucci-Cordisco E, Rovella V, Carrara S, Percesepe A, Pedroni M, Bellacosa A, Caluseriu O, Forasarig M, Anti M, Neri G, et al: Mutations of the 'minor' mismatch repair gene MSH6 in typical and atypical hereditary nonpolyposis colorectal cancer. Fam Cancer 1: 93-99, 2001

14. Agostini M, Tibiletti MG, Lucci-Cordisco E, Chiaravalli A, Morreau H, Furlan D, Boccuto L, Pucciarelli S, Capella C, Boiocchi M and Viel A: Two PMS2 mutations in a Turcot syndrome family with small bowel cancers. Am J Gastroenterol 100: 1886-1891, 2005.

15. Duraturo F, Liccardo R and Izzo P: Coexistence of MLH3 germline variants in colon cancer patients belonging to families with Lynch syndrome-associated brain tumors. J Neurooncol 129: 577-578, 2016.

16. Duraturo F, Liccardo R, Cavallo A, De Rosa M, Grosso M and Izzo P: Association of low-risk MSH3 and MSH2 variant alleles with Lynch syndrome: Probability of synergistic effects. Int $\mathbf{J}$ Cancer 129: 1643-1650, 2011.

17. Adam R, Spier I, Zhao B, Kloth M, Marquez J, Hinrichsen I, Kirfel J, Tafazzoli A, Horpaopan S, Uhlhaas S, et al: Exome sequencing identifies biallelic MSH3 germline mutations as a recessive subtype of colorectal adenomatous polyposis. Am J Hum Genet 99: 337-351, 2016.

18. Boland CR: Recent discoveries in the molecular genetics of Lynch syndrome. Fam Cancer 15: 395-403, 2016.

19. Wang Y, Cheong N, Miura M and Iliakis G: Overexpression of insulin-like growth factor (IGF)-I receptor enhances inhibition of DNA replication in mouse cells exposed to x-rays. Radiat Environ Biophys 36: 117-123, 1997.

20. Plaschke J, Krüger S, Jeske B, Theissig F, Kreuz FR, Pistorius S, Saeger HD, Iaccarino I, Marra G and Schackert HK: Loss of MSH3 protein expression is frequent in MLH1-deficient colorectal cancer and is associated with disease progression. Cancer Res 64: 864-870, 2004.

21. Loukola A, Vilkki S, Singh J, Launonen V and Aaltonen LA: Germline and somatic mutation analysis of MLH3 in MSI-positive colorectal cancer. Am J Pathol 157: 347-352, 2000.

22. Alhopuro P, Sammalkorpi H, Niittymäki I, Biström M, Raitila A, Saharinen J, Nousiainen K, Lehtonen HJ, Heliövaara E, Puhakka J, et al: Candidate driver genes in microsatellite-unstable colorectal cancer. Int J Cancer 130: 1558-1566, 2012.

23. Ryan E, Sheahan K, Creavin B, Mohan HM and Winter DC: The current value of determining the mismatch repair status of colorectal cancer: A rationale for routine testing. Crit Rev Oncol Hematol 116: 38-57, 2017.

24. Wang L, Cunningham JM, Winters JL, Guenther JC, French AJ, Boardman LA, Burgart LJ, McDonnell SK, Schaid DJ and Thibodeau SN: BRAF mutations in colon cancer are not likely attributable to defective DNA mismatch repair. Cancer Res 63: 5209-5212, 2003.

25. Carethers JM, Koi M and Tseng-Rogenski SS: EMAST is a form of microsatellite instability that is initiated by inflammation and modulates colorectal cancer progression. Genes (Basel) 6: 185-205, 2015.

26. Vasen HF, Mecklin JP, Watson P, Utsunomiya J, Bertario L, Lynch P, Svendsen LB, Cristofaro G, Müller H, Khan PM, et al: Surveillance in hereditary nonpolyposis colorectal cancer: An international cooperative study of 165 families. The International Collaborative Group on HNPCC. Dis Colon Rectum 36: 1-4, 1993.

27. Vasen HF, Watson P, Mecklin JP and Lynch HT: New clinical criteria for hereditary nonpolyposis colorectal cancer (HNPCC, Lynch syndrome) proposed by the International Collaborative group on HNPCC. Gastroenterology 116: 1453-1456, 1999. 
28. Boland CR, Thibodeau SN, Hamilton SR, Sidransky D, Eshleman JR, Burt RW, Meltzer SJ, Rodriguez-Bigas MA, Fodde R, Ranzani GN and Srivastava S: A National Cancer Institute Workshop on Microsatellite Instability for cancer detection and familial predisposition: Development of international criteria for the determination of microsatellite instability in colorectal cancer. Cancer Res 58: 5248-5257, 1998.

29. Umar A, Boland CR, Terdiman JP, Syngal S, de la Chapelle A Rüschoff J, Fishel R, Lindor NM, Burgart LJ, Hamelin R, et al: Revised bethesda guidelines for hereditary nonpolyposis colorectal cancer (Lynch syndrome) and microsatellite instability. J Natl Cancer Inst 96: 261-268, 2004.

30. Vilar E, Mork ME, Cuddy A, Borras E, Bannon SA, Taggart MW, Ying J, Broaddus RR, Luthra R, Rodriguez-Bigas MA, et al: Role of microsatellite instability-low as a diagnostic biomarker of Lynch syndrome in colorectal cancer. Cancer Genet 207: 495-502, 2014

31. Suraweera N, Duval A, Reperant M, Vaury C, Furlan D, Leroy K, Seruca R, Iacopetta B and Hamelin R: Evaluation of tumor microsatellite instability using five quasimonomorphic mononucleotide repeats and pentaplex PCR. Gastroenterology 123 : 1804-1811, 2002

32. Buhard O, Suraweera N, Lectard A, Duval A and Hamelin R: Quasimonomorphic mononucleotide repeats for high-level microsatellite instability analysis. Dis Markers 20: 251-257, 2004.

33. Lynch PM: The hMSH2 and hMLH1 genes in hereditary nonpolyposis colorectal cancer. Surg Oncol Clin N Am 18: 611-624, 2009.

34. Liccardo R, De Rosa M, Rossi GB, Carlomagno N, Izzo P and Duraturo F: Incomplete segregation of MSH6 frameshift variants with phenotype of lynch syndrome. Int J Mol Sci 18: pii: E999, 2017

35. Duraturo F, Cavallo A, Liccardo R, Cudia B, De Rosa M, Diana $\mathrm{G}$ and Izzo P: Contribution of large genomic rearrangements in Italian Lynch syndrome patients: Characterization of a novel alu-mediated deletion. Biomed Res Int 2013: 219897, 2013

36. Liccardo R, De Rosa M, Rossi GB, Rigler G, Izzo P and Duraturo F: Characterization of novel, large duplications in the MSH2 gene of three unrelated Lynch syndrome patients. Cancer Genet 221: 19-24, 2018.

37. Rasmussen LJ, Heinen CD, Royer-Pokora B, Drost M, Tavtigian S, Hofstra RM and de Wind N: Pathological assessment of mismatch repair gene variants in Lynch syndrome: Past, present, and future. Hum Mutat 33: 1617-1625, 2012.

38. Duraturo F, Liccardo R, Cavallo A, De Rosa M, Rossi GB and Izzo P: Multivariate analysis as a method for evaluating the pathogenicity of novel genetic MLH1 variants in patients with colorectal cancer and microsatellite instability. Int J Mol Med 36 : 511-517, 2015.

39. Goldgar DE, Easton DF, Byrnes GB, Spurdle AB, Iversen ES and Greenblatt MS; IARC Unclassified Genetic Variants Working Group: Genetic evidence and integration of various data sources for classifying uncertain variants into a single model. Hum Mutat 29: 1265-1272, 2008

40. Kheirelseid EA, Miller N, Chang KH, Curran C, Hennessey E, Sheehan M and Kerin MJ: Mismatch repair protein expression in colorectal cancer. J Gastrointest Oncol 4: 397-408, 2013.

41. Jansen AM, van Wezel T, van den Akker BE, Ventayol Garcia M, Ruano D, Tops CM, Wagner A, Letteboer TG, Gómez-García EB Devilee P, et al: Combined mismatch repair and POLE/POLD1 defects explain unresolved suspected Lynch syndrome cancers. Eur J Hum Genet 24: 1089-1092, 2016.

42. Zanotti KJ and Gearhart PJ: Antibody diversification caused by disrupted mismatch repair and promiscuous DNA polymerases. DNA Repair (Amst) 38: 110-116, 2016.

43. Davari K, Frankenberger S, Schmidt A, Tomi NS and Jungnickel B: Checkpoint kinase 2 is required for efficient immunoglobulin diversification. Cell Cycle 13: 3659-3669, 2014.

44. Bak ST, Sakellariou D and Pena-Diaz J: The dual nature of mismatch repair as antimutator and mutator: For better or for worse. Front Genet 5: 287, 2014

45. Schwitalle Y, Linnebacher M, Ripberger E, Gebert J and von Knebel Doeberitz M: Immunogenic peptides generated by frameshift mutations in DNA mismatch repair-deficient cancer cells. Cancer Immun 4: 14, 2004.

46. Schwitalle Y, Kloor M, Eiermann S, Linnebacher M, Kienle P, Knaebel HP, Tariverdian M, Benner A and von Knebel Doeberitz M: Immune response against frameshift-induced neopeptides in HNPCC patients and healthy HNPCC mutation carriers. Gastroenterology 134: 988-997, 2008.
47. Koi M, Tseng-Rogenski SS and Carethers JM: Inflammation-associated microsatellite alterations: Mechanisms and significance in the prognosis of patients with colorectal cancer. World J Gastrointest Oncol 10: 1-14, 2018.

48. Bilgin B, Sendur MA, Bülent Akıncı M, Şener Dede D and Yalçın B: Targeting the PD-1 pathway: A new hope for gastrointestinal cancers. Curr Med Res Opin 33: 749-759, 2017.

49. Link JT and Overman MJ: Immunotherapy progress in mismatch repair-deficient colorectal cancer and future therapeutic challenges. Cancer J 22: 190-195, 2016.

50. Dominguez-Valentin M, Nakken S, Tubeuf H, Vodak D, Ekstrøm PO, Nissen AM, Morak M, Holinski-Feder E, Martins A, Møller P and Hovig E: Identification of genetic variants for clinical management of familial colorectal tumors. BMC Med Genet 19: 26, 2018

51. Giardiello FM, Allen JI, Axilbund JE, Boland CR, Burke CA, Burt RW, Church JM, Dominitz JA, Johnson DA, Kaltenbach $\mathrm{T}$, et al: Guidelines on genetic evaluation and management of Lynch syndrome: A consensus statement by the US Multi-society task force on colorectal cancer. Am J Gastroenterol 109: 1159-1179, 2014.

52. Kanga-Parabia A, Gaff C, Flander L, Jenkins M and Keogh LA: Discussions about predictive genetic testing for Lynch syndrome: The role of health professionals and families in decisions to decline. Fam Cancer 17: 547-555, 2018.

53. Lindberg LJ, Ladelund S, Frederiksen BL, Smith-Hansen L and Bernstein I: Outcome of 24 years national surveillance in different hereditary colorectal cancer subgroups leading to more individualised surveillance. J Med Genet 54: 297-304, 2017.

54. Aissaoui S, Cartellier C, Seytier T, Giraud S and Calender A: Genetic mutation risk calculation in Lynch syndrome inheritance: Evaluating the utility of the PREMM PR., $_{1,6}$ model in Lyon: The first French study. Bull Cancer 104: 288-294, 2017.

55. Dillon JL, Gonzalez JL, DeMars L, Bloch KJ and Tafe LJ: Universal screening for Lynch syndrome in endometrial cancers: Frequency of germline mutations and identification of patients with Lynch-like syndrome. Hum Pathol 70: 121-128, 2017.

56. De Rosa M, Rega D, Costabile V, Duraturo F, Niglio A, Izzo P, Pace U and Delrio P: The biological complexity of colorectal cancer: Insights into biomarkers for early detection and personalized care. Therap Adv Gastroenterol 9: 861-886, 2016.

57. Wojas-Krawczyk K, Kalinka-Warzocha E, Reszka K, Nicoś M, Szumiło J, Mańdziuk S, Szczepaniak K, Kupnicka D, Lewandowski R, Milanowski J and Krawczyk P: Analysis of KRAS, NRAS, BRAF, and PIK3CA mutations could predict metastases in colorectal cancer: A preliminary study. Adv Clin Exp Med: 7 Aug 2018 [Epub ahead of print].

58. Murcia O, Juárez M, Rodríguez-Soler M, Hernández-Illán E, Giner-Calabuig M, Alustiza M, Egoavil C, Castillejo A, Alenda C, Barberá V, et al: Colorectal cancer molecular classification using BRAF, KRAS, microsatellite instability and CIMP status: Prognostic implications and response to chemotherapy. PLoS One 13: e0203051, 2018

59. Romera A, Peredpaya S, Shparyk Y, Bondarenko I, Mendonça Bariani G, Abdalla KC, Roca E, Franke F, Melo Cruz F, Ramesh A, et al: Bevacizumab biosimilar BEVZ92 versus reference bevacizumab in combination with FOLFOX or FOLFIRI as first-line treatment for metastatic colorectal cancer: A multicentre, open-label, randomised controlled trial. Lancet Gastroenterol Hepatol 3: 845-855, 2018.

60. Li LS, Morales JC, Veigl M, Sedwick D, Greer S, Meyers M, Wagner M, Fishel R and Boothman DA: DNA mismatch repair (MMR)-dependent 5-fluorouracil cytotoxicity and the potential for new therapeutic targets. Br J Pharmacol 158: 679-692, 2009.

61. O'Neil BH, Wallmark JM, Lorente D, Elez E, Raimbourg J, Gomez-Roca C, Ejadi S, Piha-Paul SA, Stein MN, Abdul Razak AR, et al: Safety and antitumor activity of the anti-PD-1 antibody pembrolizumab in patients with advanced colorectal carcinoma. PLoS One 12: e0189848, 2017.

62. von Knebel Doeberitz M and Kloor M: Towards a vaccine to prevent cancer in Lynch syndrome patients. Fam Cancer 12: 307-312, 2013.

his work is licensed under a Creative Commons Attribution-NonCommercial-NoDerivatives 4.0 International (CC BY-NC-ND 4.0) License. 